25.

\title{
MARRIAGE PATTERNS IN ANKOLE, SOUTH - WESTERN UGANDA
}

\author{
James P.M. NTOZI and John KABERA \\ Makerere University, Uganda
}

\section{ACKNOWLEDGEMENTS}

The authors thank Etienne van de Walle, Douglas Ewbank, Koffi Ekouevi and other members of the editorial committee for their valuable comments on earlier drafts of the paper. Financial, computing, office and secretarial support to the authors was provided by the Population Studies Center, the Population Council and the Rockefeller Foundation to whom they are grateful. International Development Research Centre (IDRC) of Canada financed the 1984 Ankoic survey on which the study is based. 


\begin{abstract}
This paper studies marriage patterns and systems in Ankole. Discussed in the study are age at marriage, proportion married, marriage dissolution, remarriages, types of marriage and bridewealth. The paper finds that most of the marriage patterns are among the major causes of high fertility in the area.
\end{abstract}

\title{
INTRODUCTION
}

Recent studies have shown that East Africa is one of the sub-regions with the highest fertility levels in Africa (ECA, 1979). Of the many societies in East Africa with particularly high rates of fertility are the Banyankole of south-western Uganda. The Banyankole have maintained the highest fertility rates in the country for the last three decades.

Some research has been done to explain the high fertility situation in the area. Arya et al. (1973) studied the medical aspects of fertility in the area and found relatively little incidence of sexually transmitted diseases which have caused secondary sterility in some of the neighboring societies. For instance, they found that Teso in north-eastern Uganda had much higher prevalence, which was perhaps responsible for the low fertility in the area.

Using data from the same survey, Costello (1986) examined the nutritional factors in Ankole and concluded that the status of nutrition was low, which could have been responsible for the high infant mortality levels, and indirectly (through shortened birth intervals) for high fertility in the area. In another study Sheku (1987) recently investigated pathological sterility and indicated that it could be higher than what Arya et al. (1973) had found and hence depress fertility in the area. But fertility still remains high, which renders Sheku's findings questionable.

Unfortunately, few of the cultural variables of fertility in Ankole have been studied. This paper uses recent data to study marriage patterns and systems in Ankole. The study gives background characteristics of the area, briefly describes data sources and presents recent fertility experience. Various marriage patterns are discussed and in some parts of the paper related to fertility. We conclude by suggesting a research agenda to fill the present data gaps.

\section{SOCIO-CULTURAL SETTING}

Ankole is situated across the equator in south-western Uganda, about 100 kilometers west of Lake Victoria and immediately south of Lakes Edward and George. Its size is about 16,182 square kilometers. Administratively, the area was one of the four interlacustrine kingdoms of Uganda abolished in 1967. In the 1970s Ankole was divided into two districts, namely Mbarara to the east and Bushenyi in the west (Map 1). 
THE PROJECT AREA - ANKOLE

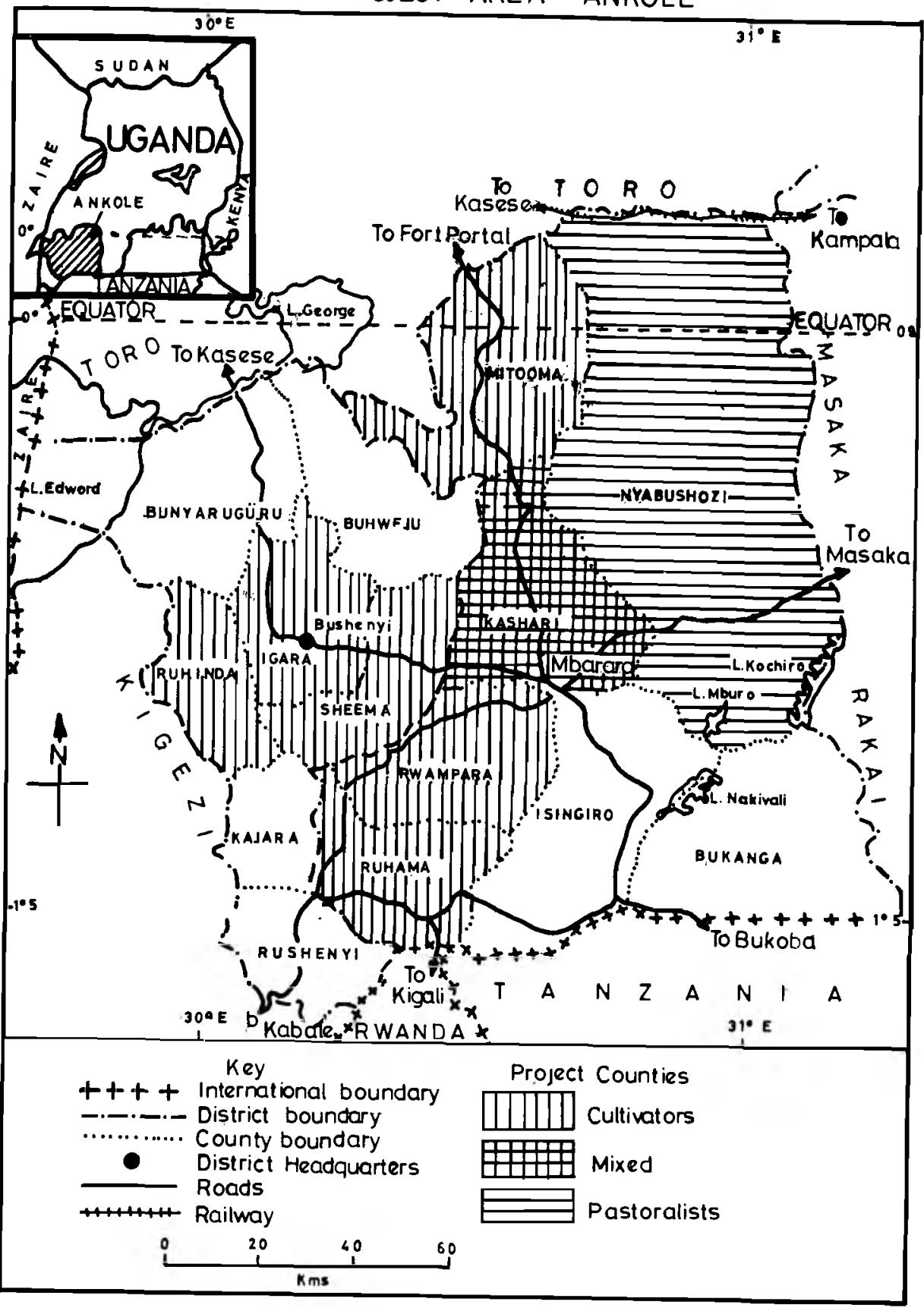


28.

The people of Ankole are called "Banyankole" and speak "Runyankole", one of the major Bantu dialects in Uganda.

The "Bairu", who form the large majority, are cultivators of coffee and tea as cash crops and bananas, maize, millet, beans, sweet potatoes and groundnuts as cash and food crops. They are relatively permanently settled.

A second group is the "Bahima", who are pastoralists looking after the famed Ankole longhorned cattle for food and cash. In the past, their occupation made them nomads in search of good pasture and water for their cattle, especially in dry seasons. Recently many of the Bahima have tended to have semi-permanent and permanent settlements. Interposed between the two main groups are the mixed farmers who have evolved by intermarriages or by economic practice of keeping cattle and growing crops.

All three groups are rural, traditional and at the same stage of socio-economic development. Levels of literacy, education, employment status, urbanization and women's position are low. The Banyankole are organized on a patrilineal clan structure and practice patrilocal residence. Although clans are exogamous, they tend to marry within the same ethnic group.

The last four decades have witnessed dramatic population changes in Ankole. Between the 1948 and 1980 censuses, total population of the area more than trebled from 400,924 to $1,212,822$. This rapid growth was due to high and perhaps increasing fertility, reduction in mortality and heavy migration into the area during the period.

\section{SOURCES OF DATA}

Like the rest of Uganda, Ankole has suffered from lack of demographic data in the past, mainly due to the political

instability that has bedeviled the country for the last two decades. Information on fertility and marriage has been more difficult to get. Registration of births, deaths and marriages has been compulsory by statute for some time now, but inoperative. The early demographic inquiries of 1911,1921 and 1931 did not yield much useful data because they were mere head counts. Modern censuses of 1948 and 1959 had little information on the subject of nuptiality. The 1969 census had a lot of information on fertility levels but little on marriage patterns. Deductions can be made for the area from the tabulations on marital status for western Uganda, of which Ankole is a part. Fortunately, Ankole data are part of the little that was saved from the Uganda 1980 census. However, most of this data has not been tabulated due to lack of computing facilities in the country, with the exception of information on fertility from the Katende study (1983) on Bushenyi district and the tables on marital status for Arkole produced by the census office. 
It was against this background of inadequate census data that four demographic surveys were held. The first one was done in 1970-71 by Arya and Taber (Arya et al., 1973). Its objective was to investigate socio-medical factors explaining high fertility in Ankole, as compared to low fertility in Teso. The survey collected data on fertility levels, marriage patterns and pathological sterility.

More detailed information was collected by surveys conducted in 1984 and 1985 by the authors. The 1985 study of 1000 ever-married women in reproductive age groups was designed to examine the value of children in the area. One of the sections of the questionnaire was devoted to marriage patterns and another to maternity histories. However, most of the survey data have not been processed and tabulated. Only household retrospective and current fertility data of 1664 women have been tabulated and will be used in this paper. Also some preliminary data on age at first marriage and types of unions for 1000 women are available.

Most of the data in this paper are drawn from the 1984 survey sponsored by the International Development Research Centre (IDRC) of Canada. The survey was divided into two parts. In early 1984, we carried out a small exploratory study of 44 old men and women to learn about the customs, norms, and taboos in the society. This was immediately followed by a larger survey, the main objective of which was to investigate some of the determinants of fertility in Ankole. Among the factors studied were marriage patterns and systems. The data collected included background variables, marriage patterns, birth histories, value of children, desired number of children, contraception, and cultural obligations and taboos. A sample of 683 evermarried women aged 15 years in 600 households was selected. Of the sample, 400 households were drawn from four cultivators' parishes, and, 100 each from a pastoralists' and a mixed peasants' parish. The number of households selected from each group was determined by its relative population size.

The fertility information collected in the 1984 study was from two sources. First the household record form, which asked all women aged 12 years and above questions on children ever born alive and births in the past year, was used. Second, the World Fertility Survey type of questions on birth histories were put to each of the 683 ever-married women. In addition, the household record form yielded data on marital status of all females in the 600 households. Further, the individual women questionnaire probed marriage histories in detail and coverd questions on types of unions and number of co-wives.

\section{FERTILITY IN ANKOLE}

Before we discuss the marriage patterns in Ankole, it is important to briefly summarize past fertility experience of the area. It has bcen observed that for scveral decades Ankole has maintained the highest fertility in Uganda and one of the highest in East Africa. The past 
30.

TABLE 1

ADJUSTED FERTILITY RATES FOR ANKOLE IN 1959, 1969, 1980, AND 1985

\begin{tabular}{llllll}
\hline AGE & $\begin{array}{l}1959 \\
\text { CENSUS }\end{array}$ & $\begin{array}{l}1969^{*} \\
\text { CENSUS }\end{array}$ & $\begin{array}{l}1980^{* *} \\
\text { CENSUS }\end{array}$ & $\begin{array}{l}1985 \\
\text { SURVEY }\end{array}$ & $\begin{array}{l}1985 \\
\text { SAMPLE WOMEN }\end{array}$ \\
\hline $15-19$ & .151 & .155 & .074 & .074 & 472 \\
$20-24$ & .397 & .359 & .342 & .361 & 375 \\
$25-29$ & .365 & .388 & .412 & .417 & 250 \\
$30-34$ & .277 & .355 & .364 & .389 & 158 \\
$35-39$ & .234 & .270 & .248 & .302 & 148 \\
$40-44$ & .041 & .135 & .130 & .128 & 126 \\
$45-49$ & .137 & .047 & .082 & .074 & 135 \\
TOTAL & 1.602 & 1.709 & 1.652 & 1.745 & 1664 \\
TFR & 8.0 & 8.5 & 8.3 & & \\
\end{tabular}

* See : Republic of Uganda, 1976, Table 2.5

** For Bushenyi alone, see : Katende (1983), Appendix Table 5.5

TABLE 2

ESTIMATED MARITAL FERTILITY RATES FOR ANKOLE

IN 1969 and 1985, and 1985/69 RATIOS

\begin{tabular}{llll}
\hline AGE & 1969 & 1985 & $1985 / 69$ RATIOS \\
\hline $15-19$ & .337 & .440 & 1.31 \\
$20-24$ & .415 & .532 & 1.28 \\
$25-29$ & .413 & .460 & 1.11 \\
$30-34$ & .372 & .401 & 1.08 \\
$35-39$ & .283 & .310 & 1.10 \\
$40-44$ & .142 & .129 & ) \\
$45-49$ & .050 & .074 & ) \\
& & & \\
TFR & 10.1 & 11.7 & \\
\hline
\end{tabular}


fertility situation in the area is summarized in Table 1 . The table presents age-specific fertility adjusted by the Brass P/F technique (United Nations, 1983). It is clear that the four data sources agree that fertility has remained high at all ages, giving total fertility rates of above 8 between 1959 and 1985. A comparison of 1959, 1969, and 1985 rates for the whole of Ankole shows that fertility had been constant or slowly increasing in most age groups.

Perhaps a more interesting analysis would be to study the age specific marital fertility rates of the area. They were computed by dividing the rates in Table 1 by the corresponding proportions ever married in Table 6. We then obtained the ratios of 1985 to 1969 rates. The results are given in Table 2 and exhibit even higher levels of fertility in all age groups, leading to total marital fertility rates of 10.1 and 11.7 in 1969 and 1985, respectively. The ratios in the table represent a moderate increase in fertility over the period and an overall rise of between 10 and 20 percent. It is likely that the decreasing ratios with age reflect underestimation of the proportion of dissolved unions at old ages due to poor age reporting.

In addition, Figure 1 displays age fertility patterns for 1959, 1969, 1980 and 1985, which show a plateau shape between ages 20 and 35 for the last three surveys. The 1959 curve displays an early peak. As will be explained later, marriage patterns are largely responsible for the shape of the curves.

Further, it is remarkable that data from 1985 survey exhibited in Table 3 and Figure 2 show that fertility varies with economic groups. While the cultivators' (Bairu) women have the highest total fertility rate of 10.3, the pastoral (Bahima) women reported the lowest level of 7.1. Women of the mixed farmers have a total fertility of 9.4 children per woman. In addition, Figure 2 displays a fertility plateau between ages 20 and 35 for the Bahima women and a late peak for the cultivators and mixed farmers. Although the fertility curve of the cultivators rises higher, it falls faster than that of the mixed farmers after age 35. Prominent among the factors responsible for these differences are the marriage patterns and systems, some of which vary between the groups and are discussed in the following sections of the paper.

\section{MARRIAGE PATTERNS AND SYSTEMS}

Kingsley Davis' and Judith Blake's (1956) pioneering work on proximate variables explained the crucial role of marriage patterns and systems in influencing fertility of a society. They pointed out specific aspects of marriage that affect fertility like : age at marriage, proportion married, marital dissolution and remarriage. Recently, John Bongaarts and Robert Potter (1983) emphasized these variables and quantified them. Studies of societies in developing countries, especially in Africa, have indicated that other marriage factors, such as types of marriages and bridewealth may influence fertility. 


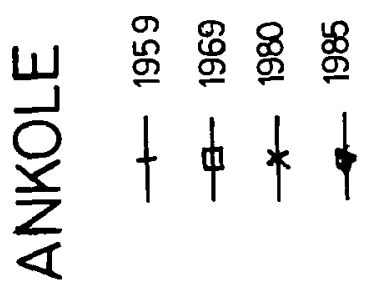

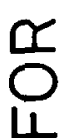

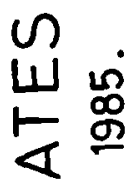

$\alpha$ g

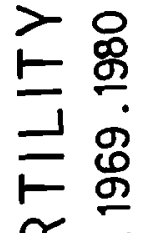

U

山 으

$\square$

山

$\frac{1}{8}$

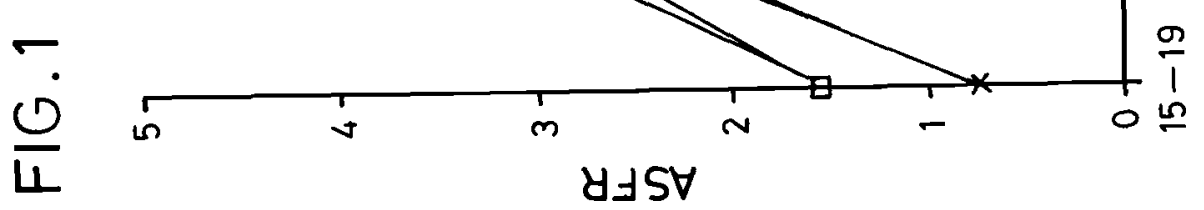


TABLE 3

ADJUSTED FERTILITY RATES AMONG THE DIFFERENT ECONOMIC GROUPS OF WOMEN IN ANKOLE, 1985

\begin{tabular}{|c|c|c|c|c|c|c|c|c|}
\hline AGE & $\begin{array}{l}\text { RATES } \\
\text { FOR } \\
\text { BAIRU } \\
\text { (CULTIV) }\end{array}$ & $\begin{array}{l}\text { BAIRU } \\
\text { SAMPLE } \\
\text { WOMEN }\end{array}$ & $\begin{array}{l}\text { RATES } \\
\text { FOR } \\
\text { BAHIMA } \\
\text { (PASTOR) }\end{array}$ & $\begin{array}{l}\text { BAHIMA } \\
\text { SAMPLE } \\
\text { WOMEN }\end{array}$ & $\begin{array}{l}\text { RATES } \\
\text { FOR } \\
\text { MIXED } \\
\text { FARMERS }\end{array}$ & $\begin{array}{l}\text { MIXED } \\
\text { SAMPLE } \\
\text { WOMEN }\end{array}$ & $\begin{array}{l}\text { RATES } \\
\text { FOR } \\
\text { ALL } \\
\text { WOMEN }\end{array}$ & $\begin{array}{l}\text { TOTAL } \\
\text { SAMPLE } \\
\text { WOMEN }\end{array}$ \\
\hline $\begin{array}{l}15-19 \\
20-24 \\
25-29 \\
30-34 \\
35-39 \\
40-44 \\
45-49\end{array}$ & $\begin{array}{l}.107 \\
.468 \\
.515 \\
.448 \\
.322 \\
.157 \\
.039\end{array}$ & $\begin{array}{r}112 \\
111 \\
64 \\
42 \\
42 \\
32 \\
32\end{array}$ & $\begin{array}{l}.077 \\
.307 \\
.329 \\
.321 \\
.218 \\
.099 \\
.062\end{array}$ & $\begin{array}{r}191 \\
159 \\
110 \\
54 \\
51 \\
61 \\
60\end{array}$ & $\begin{array}{l}.049 \\
.332 \\
.458 \\
.407 \\
.366 \\
.152 \\
.117\end{array}$ & $\begin{array}{r}169 \\
105 \\
76 \\
62 \\
55 \\
33 \\
43\end{array}$ & $\begin{array}{l}.074 \\
.361 \\
.417 \\
.389 \\
.302 \\
.128 \\
.074\end{array}$ & $\begin{array}{l}472 \\
375 \\
250 \\
158 \\
148 \\
126 \\
135\end{array}$ \\
\hline TOTAL & 2.056 & 435 & 1.413 & 686 & 1.881 & 543 & 1.745 & 1664 \\
\hline TFR & & 10.3 & $\overline{7.1}$ & & 9.4 & & 8.7 & \\
\hline
\end{tabular}

TABLE 4

PROPORTION SINGLE WOMEN IN ANKOLE IN $1969,1980,1984$, and 1985

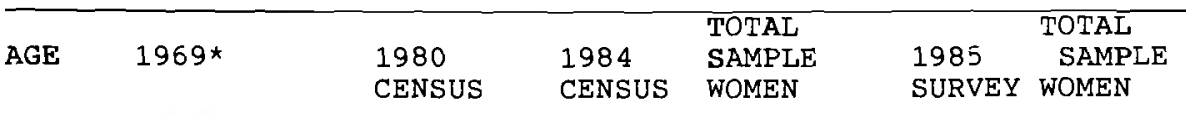

\begin{tabular}{lrrrrrr}
\hline $10-14$ & 98.2 & 99.2 & 99.7 & 310 & 99.2 & 592 \\
$15-19$ & 54.0 & 71.5 & 78.7 & 288 & 83.2 & 495 \\
$20-24$ & 13.4 & 19.6 & 34.0 & 237 & 32.1 & 383 \\
$25-29$ & 6.1 & 6.4 & 20.9 & 155 & 9.4 & 254 \\
$30-34$ & 4.6 & 3.9 & 8.9 & 135 & 3.1 & 162 \\
$35-39$ & 4.7 & 2.6 & 2.6 & 76 & 2.7 & 150 \\
$40-44$ & 5.1 & 2.6 & 1.2 & 84 & .8 & 128 \\
$45-49$ & 6.0 & 2.0 & - & 47 & - & 136 \\
\multicolumn{1}{|l}{} & & & & & 21.5 & \\
SMAM & $17.7(18.1) \star \star$ & 19.8 & 22.3 & & 20.7 &
\end{tabular}

ऋ Western Uganda, see : Republic of Uganda

$\star \star$ For Ankole 


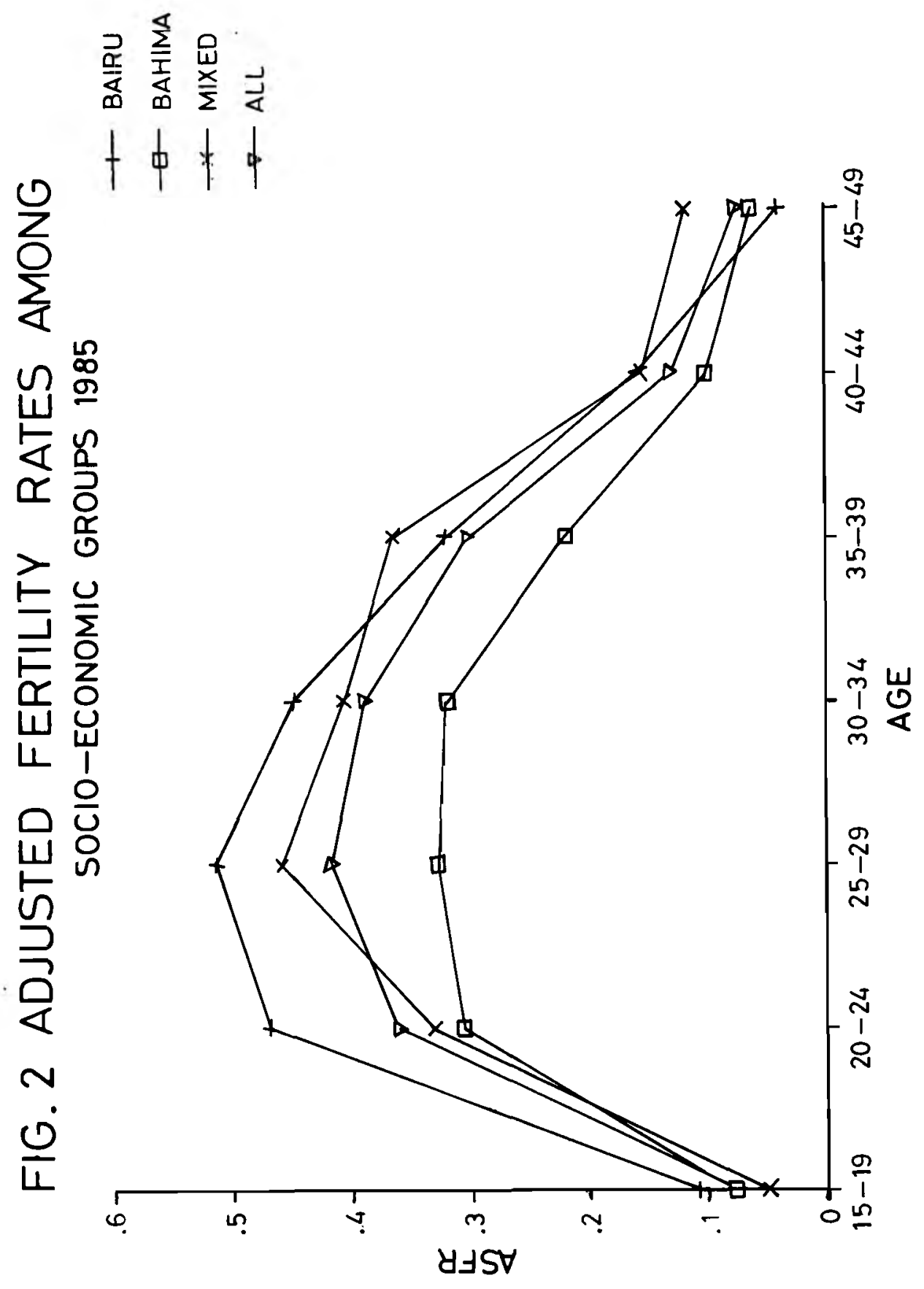




\section{Age at marriage}

A good indicator of age at marriage is the mean age at first marriage. Unfortunateley, it is not easy to calculate this index directly for many developing countries, because of lack of requisite information. In the absence of necessary data, several indirect methods have been developed to estimate age at marriage for developing countries. One such technique was proposed by Hajnal in 1953. It utilizes percentages of single women to compute a "singulate mean age at marriage" (SMAM) from census or survey data. Table 4 displays proportions single among women in 1969 for western Uganda, and 1980, 1984 and 1985 for Ankole, which are used in the application of the method. It is clear from the table that the proportions single increased between 1969 and 1985 at the young ages and dropped at older ages.

The resulting singulate mean age at marriage for Ankole in 1969 was 18.1 years. This is a fairly early age at first marriage, reflecting high fertility in the area at the time. Eleven years later, in 1980, Bushenyi district recorded 19.7 years and Mbarara 19.8 years, giving an average of 19.8 years for Ankole. This age seems to have continued increasing to between 21 and 22 years by 1985. Similarly, the median age increased from 18.4 in 1969 to 20.7 in 1985 . Evidence of a gradual shift from an early peak in 1959 to a broad peak in 1969 and to a later-broad peak in 1985 fertility patterns shown in Table 1 and Figure 1 implies that this rise has taken place.

The reasons for the increase are largely socio-economic. Between 1969 and 1980 , the proportion educated among females increased dramatically. For instance, the percentage of females aged 15 and above who had been to school was as low as 12.4 in 1969 compared to 34.7 in 1980 , an increase of almost three times in only eleven years. Like elsewhere in Africa, this Western education was accompanied by Western values which discouraged women from marrying too early.

Other Western values included modern religions, notably Catholicism and Protestantism, which spread fast. In the 1959 census, Christianity accounted for 51 percent and traditional religions for 47 percent of the population aged 16 and over (Uganda, 1961). The 1984 survey shows no one who belonged to traditional religions while Christians were 98 percent. One of the main Christian churches' objectives was to convert people from their "sinful" traditional ways to Western values. This is likely to have had a dramatic impact on the attitudes of many people in the area, especially toward issues like marriages which had to be conducted in church. A Christian parent could not present a very young daughter to church for a Christian wedding when he knew that the church discouraged it.

An increase in age at first marriage is logically associated with a decrease in fertility rates, since it reduces the time available for the woman to bear children. However, fertility levels in Ankole seem not to have been decreasing as the age at marriage was going up. Once married a woman is required by culture to start bearing children immediately lest she be declared barren or 
divorced. Further, unlike in many West African societies, there is no post-partum sex taboo in Ankole to allow women to space their children. Instead, there are strong customs in the area which oblige a woman to have sex with her husband starting several days after delivering a baby and continuing at certain stages of child development. For instance, she is supposed to have sex with her husband to honor the birth of the child four days after the event, and other events like the naming, seating, showing of milk tooth, crawling, and the first steps of the child. There are over twenty other events which have to be celebrated by sex. This practice tends to increase coital frequency and hence raises chances of conception a few months after child birth for the women with short amenorrhea. In addition, almost no woman in this society practices effective modern contraception. In our 1984 survey, most of those who claimed to have used contraceptives had applied traditional ones which are largely dependant on beliefs and are ineffective. Besides, Banyankole women consider children a blessing and a source of future insurance.

A more direct method of studying age at first marriage is to use reports of ever married women aged 15-49. The outcome of the method applied to the 1984 survey is exhibited in Table 5. The table indicates that the reported mean age at first marriage was much lower than the above indirect estimates. This is a reflection of gross under-reporting of ages typical of African women. However, since this error seems common to a!l women, it is possible to use the reported ages for comparing women of different characteristics. Another source of error in the data is the truncation effect. To take care of this error; mean ages for women aged 25 and above were computed for those who reported to have married before age 25 . Largely because only 2.9 percent married after age 25 , there is hardly any difference which reflects the lack of a major truncation effect on the results in Table 5. It can be seen from this table that the mean age at first marriage was reported by these women to range from 15 years for those aged $35-$ 39 to 18 years for age groups $25-29$ and $45-49$, giving an overall average age of 17 in 1984 . Interestingly, this early age compares closely with the Kenyan average of 17.1 years associated with a total fertility of 8.1 in 1977-78 (Republic of Kenya, 1980), which is close to the Ankole level. The closeness is not surprising given that the Kenyan data are affected by similar age misstatements. Further, it is worth noting that there is no trend of age at marriage consistent with ages of women. One expected a declining trend between ages 25 and 49 due to some modernization variables. The lack of trend may be a reflection of reporting of an ideal or expected age by all cohorts.

The main reason for the young age at first marriage is cultural. Ankole society is still highly traditional. Girls are culturally supposed to get suitors and marry as soon as their breasts grow and they start menstruating. Until three decades ago Banyankole parents were reluctant to send their daughters to school because they believed that the girl's place was in the home looking after her husband and producing and raising children. Hence, fathers were anxious to marry off their daughters as soon as appiopriate suitors were available. 
37.
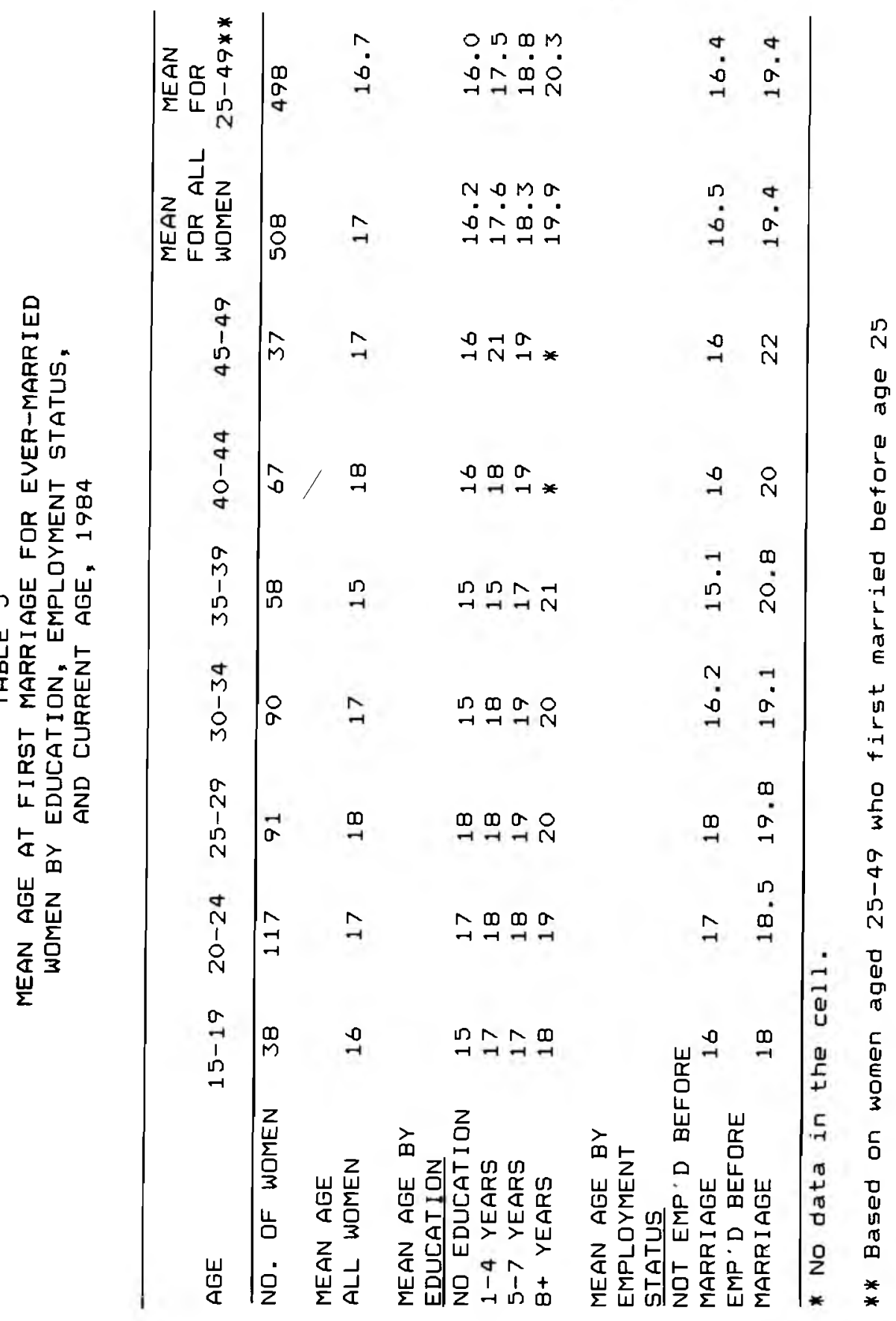
Although the mean age at first marriage is low, variations exist because of several factors. The first variable is level of education of women. Table 5 clearly displays that women without formal education married at the lowest age, 16, while those with secondary education married at the highest reported mean age, 20 years. The table shows a positivie relationship between years of education and age at first marriage in almost all age groups except the oldest (45-49). Unlike girls at school, who have to wait to complete education before marriage, those out of school are encouraged to marry when suitors are available. However, it is possible that educated women's reports of higher ages are more of a reflection of accuracy of the age statements than true differences between ages at marriage of the educated and uneducated.

In addition, religion has been another factor influencing age at first marriage. Not surprisingly, Moslem women reported having first married at an average age of 15.8, the Catholics at 16.5 and the Anglicans at the highest age of 17 . Until recently, it was common for Muslim fathers to marry off their daughters at puberty. They were very slow at sending their daughters to school, where they could delay marriage. Even for those in school it was not uncommon to hear of gir's leaving school because a suitor had been found. In contrast, the Anglicans encouraged their daughters to go to school. In between these two religions fell the Catholics who are more conservative and traditional than the Anglicans. However, they started sending their daughters to school earlier than Moslems.

It has been observed in some African surveys that childhood residence of women influences their age at first marriage (Republic of Kenya, 1980). Our findings indicate that the women who grew up in rural areas of Ankole married at a mean age of 16.8 , which is lower than the 18 years reported by those who grew up in relatively urban centers. Those born in urban centers were less bound by traditional custom to make them marry early. Besides, they were more likely to go to school.

The pattern of work was also related to age at first marriage. The 1984 data in Table 5 indicate that women who never worked outside their parents' homes married at lower ages than those who worked before marriage in all age groups. The former group had no employment to prevent them marrying at an average age of 16.5. Those who were employed delayed their marriage because they wanted to work for some time first and they were at school before their employment. On average, they first married at 19.4 years of age.

An interesting finding is that although the cultivators and pastoralists live completely different lives economically, the mean age reported by their women in 1984 is the same, 16.8 years. This is perhaps because both groups are still highly traditional in attitudes towards marriage of their daughters. In addition, the roles of their women in marriage are the same, being housewives and producers of children. Further, the modernization factors discussed above do not vary between the groups. 
39.

\section{Proportion married}

In all societies of sub-Saharan Africa, the primary purpose of marriage is procreation. Most societies in Africa do not tolerate women who fail to produce in the first few years of their marriage. Such women would be returned to their parents and bridewealth paid back. In contrast, motherhood outside wedlock is discouraged in most societies. Consequently, marital fertility is higher than non-marital fertility in these societies.

Similarly, the main objective of Banyankole marriages is to produce as many children as possible (Ntozi et al., 1986). Their proverb says it all, "Omukazi skishumba akitekwamu omwana"" (the essence for a woman to stay in marriage is to produce children). If a bride spends about one year without being pregnant, tradi-tional doctors are called in to assist. After a few years she is declared barren and the husband is free to replace her with a "productive" wife.

If the "barren" wife is well behaved, hard working and liked by the husband's family, she may continue to stay with the man while she continues to try for pregnancy. But keeping her is entirely the husband's option. He is free to send her back to her parents and demand his bridewealth back (Ntozi et al., 1986).

On the other hand, motherhood outside wedlock is frowned upon and used to be considered a curse. In the past, a pregnant single girl was killed by her clan before it was engulfed by the curse. Even today, premarital pregnancy is considered shameful and often punished by banishment of the girls from home to look for the men responsible for their pregnancies and marry them. Often the mother of the girl is reprimanded for failing in her duty of looking after her daughter well.

In Ankole, it is the wish of parents that every aduit girl is married off as soon as possible. This desire is frequently expressed in two popular proverbs : "Enyamwonyo kwekura eriibwa" (when a banana ripens it is consumed) or "Omwishiki kwakuara ashwerwa" (an adult girl should be married off). Parents feel successful in life and get relief and fulfillment in marriage when their daughters or sons marry. At a wedding of a son, one old man who had waited a long time for his only son to marry, publicly declared : "If I die now I would die a happy man because I have performed my best function in life". It is believed that an unmarried adult girl can be an embarrassment in several ways. First, she may get pregnant before marriage and thereby become a shame and curse to the clan. Second, if she died before marriage, some embarrassing rituals such as passing the corpse through the back entrance (Niozi et al., 1986) and "Okugyera empango" (a ritual for breaking her virginity) are necessary to stop a curse on the clan (Byaruhanga-Akiiki, 1978).

Because the traditions of Ankole put a high premium on marriage of their children, there is a high percentage of married women and men in the area. Table 6 derived from the 1980 census and the household surveys of 1984 and 1985 shows that the percent ever married among women 


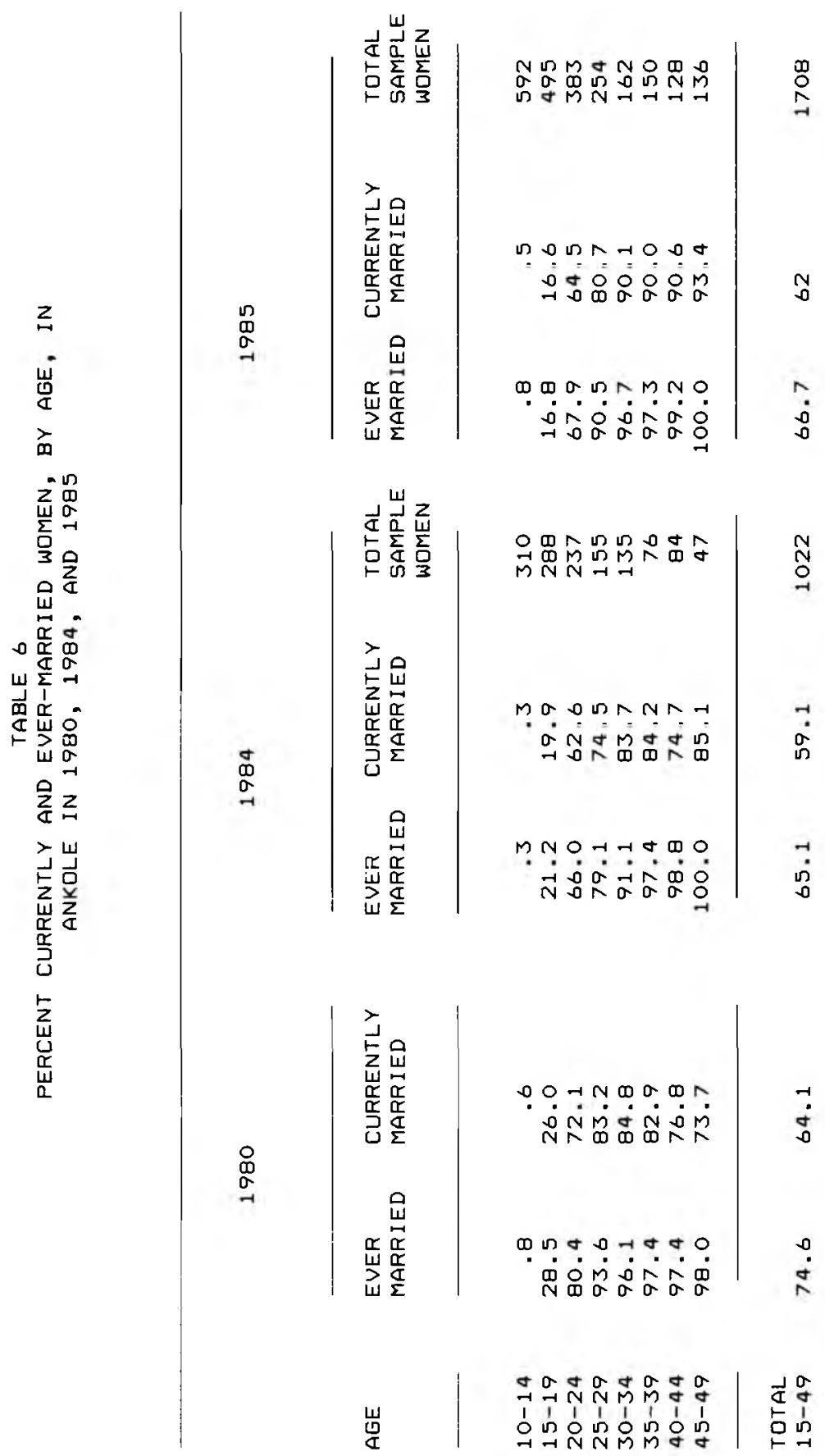


rises fast with age and exceeds 90 percent by age 30 . In the reproductive groups no woman was reported single at age 45 and above in the 1984 and 1985 surveys. This might mean universal marriage by this age. Hence, the low figure of 79 percent for age group 25-29 in 1984 was most improbable and due to misreporting. In addition, the elders of Ankole in a separate interview strongly wanted the practice of universal marriage to continue (Ntozi et al., 1986). On the other hand, it may reflect underreporting of widowhood.

\section{Marriage dissolution}

This intermediate variable of fertility consists of divorce, separation and widowhood. In traditional societies, when a woman is in one of these conditions, her exposure to pregnancy is suspended or stopped completely.

i) Divorce and separation : Dissolution of marriage in Ankole is a painful affair. The traditional conjugal system discourages divorce and separation, except for barren wives. As expected of a patrilineal culture, women are supposed to refrain from conflicting with their husbands. First, serious conflicts often arise if a woman refuses her husband sex. Second, some courageous women fail to tolerate their husbands' frequent bad habits, such as beatings, rebukes and abuses and decide to argue with them. Third, wives can disobey husbands. Further, husbands can become too harsh with their wives, despite the wife's patience and tolerance.

In the event of serious conflicts, the man's elders help to reconcile the two, mainly through constant counselling and advice. Many marriages are saved at this stage. Should this fail, the husband would send the wife back to her parents, "okushenda omukazi", or the woman voluntarily goes back to her parents' home, "okwangana". This is the stage equivalent to temporary separation in the Western sense. Believing strongly that their daughter's place is in her husband's home with her children, the parents of the woman would invite their son-in-law to their home without delay. The aggrieved party would put its case before the elders, composed of relatives, friends and neighbors of the woman's parents. The defending side is also given full opportunity to respond. If the wife is found guilty, her parents will pay a fine to the husband before he takes her báck. On the other hand, if the man was guilty, he will be fined before he gets his wife back. The fine ranges from a few pots of beer to a bull, depending on the seriousness of the case. The couple is then counselled in ways of avoiding future marriage conflicts.

This arrangement is satisfactory and has saved a large majority of unstable marriages in the area. However, in a small but growing number of cases, where the disagreements and conflicts are too serious for the elders to resolve, a man becomes incompatible with his wife; separation is then allowed. 
Sometines the separation can be temporary. Reconciliation can still be possible after several months of estrangement. But if a woman is found to be a witch, abusing the parents-in-law or guilty of equivalent misbehavior, the husband's family will not

tolerate her. The husband will divorce her ("okubinga omukazi"). Divorce becomes effective if it is followed by return of bridewealth ("okuzimuura enjugano"). Return of bridewealth severs all marital bonds and withdraws sexual rights of the man over the woman. It is equivalent to modern dissolution of marriage in court. The woman is therefore free to marry another man who would pay bridewealth. In cases where the parents of the woman are poor, bridewealth from the new suitor is used to pay the former husband back. The children of the dissolved marriage will belong to the first husband and the woman is not allowed to go with them to the second marriage.

Because a lot of effort is put into saving marriages, Ankole has a low rate of divorces and separation. This is displayed by the low percentages in Table 7, which are in single digits for 1980, 1984 and 1985. Similar patterns have been observed in many African areas with high fertility regimes. Although there is no pattern consistent with age of women, the 25-29 age group seems to display relatively higher divorce rates than other ages. This is perhaps the age when women start facing serious marital problems, which they do not know how to handle. As they get older, they mature and learn to minimize their marital difficulties.

In addition, responses from ever-married women in 1984 reveal that only 10.7 percent had divorced their first husbands. The reason for this pattern may be that those who are married traditionally and hence more conditioned by the traditional ways of resolving marital conflicts are less apt to divorce. Further analysis of the 1984 data shows that more educated and employed women have a higher tendency to divorce and separate than the rest.

ii) Widowhood : Marriage can be terminated by death of a husband. In many African societies widowhood depresses fertility more than divorce and separation because the cultural systems tolerate and help women who opt to remain widows, especially if they are in their late reproductive ages or older and have old children. Their old sons can look after them and hence do not need to look elsewhere for economic support. The same system exists in Ankole.

On the other hand, the Banyankole practise levirate. Widows are inherited by a brother-in-law in most cases. In a few instances, a step-son who is equal in age or older may take over the widow. Since this is done immediately after the funeral rites of the deceased husband, the widowhood period tends to be too short to disrupt reproductive processes of the woman. However, due to the erosion of cultural values, the levirate system is losing ground.

A surprising result in Table 7 is that although this society has high male mortality (Uganda, 1976) the percentage widowed is shown to be low in 1980, 1984 and 1985. This could be an indication of a strong presence of levirate culture. Most widows remarried in this system might 


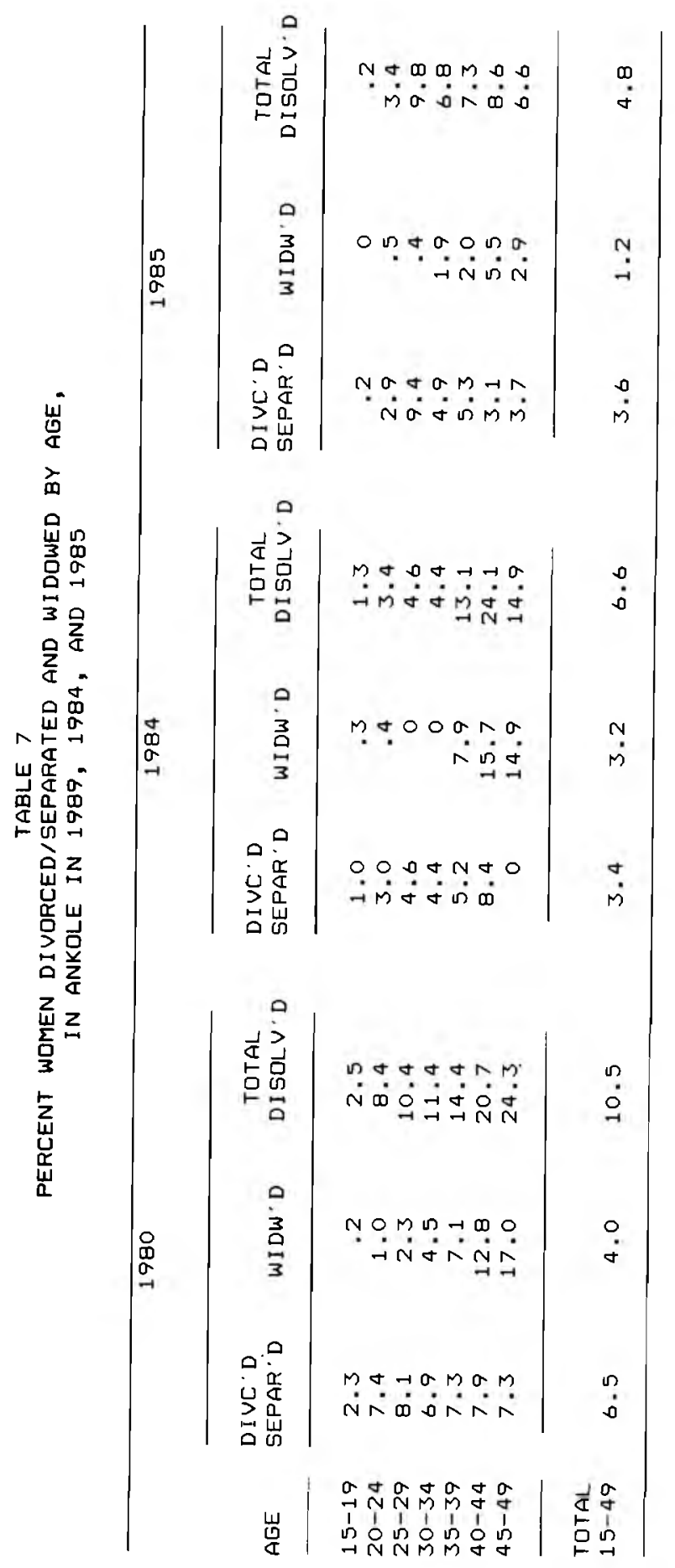


not have reported loss of former husbands. For instance, detailed interviews of ever-married women of reproductive ages in 1984 reported only 12.6 percent widowed from first marriage.

\section{$\underline{\text { Remarriages }}$}

The impact of marriage dissolution on fertility is reduced by remarriages. In Ankole the system of remarriages is practised in several ways. First, young widows are supposed to be inherited by a brother-in-law or step-son. This is because once married, women belong to their husbands' family and can only return to their parents if the bridewealth is also returned to the husbands' family. Since bridewealth is usually taken from family property, all the brothers of the man have some sexual rights over his wife (Elam, 1973 ; Ntozi et al., 1986). When the man dies it becomes easy for one of the brothers to take over his widow. The levirate culture was evolved to benefit and protect a widow and her children, who are supported by the new husband as part of his family. Old widows who can no longer produce are left alone to stay in their deceased husband's house with their children, some of whom may be old enough to support them and their young siblings.

Second, divorced women are expected to remarry as soon as possible. Often the bridewealth paid by the suitor is used by her poor relatives to pay back her estranged husband. Failure of the divorced woman to remarry causes a lot of psychological and social stress to her. This unhappiness often develops into quarrels between her and some relatives, notably sisters-in-law and step-mothers. Hence, an effort is made by her relatives to encourage her to remarry immediately when it becomes clear that reconciliation with her husband is impossible. Perhaps evidence of this is the high percentage ( 36.4 percent) of divorcees remarrying reported in the 1984 survey. This shows that women keep on trying to remarry instead of staying with relatives as divorcees.

\section{Tvpes of marriages}

i) Monogamy and polygyny : In most of Africa there are two types of marriages : monogamy and polygyny. A recent study by Pebley (1986) showed that the prevalence of polygyny in some parts of Africa is very high. For instance, in Senegal in the 1970 s the ratio of currently married women to men was 147 to 100 . The 1984 and 1985 surveys indicate that 27.3 percent and 31.1 percent, respectively, of the ever-married Banyankole women aged 15-49 lived in polygynous unions.

The reasons for Ankole to have this sizeable proportion of women in polygynous marriages are many. First, the most common ground for men to acquire additional wives is barrenness of the first wife. As one old woman told us, "Ekitazaara kicweka" (if a woman does not produce children the family and clan would disappear). Banyankole traditions encourage a man to marry a second wife if the first one fails to produce children. Similarly, if the first wife does 
45.

not produce some sons, a Munyankole man has a traditional right to get another wife to produce them. A man needs sons to continue his lineage into the future, in this patrilineal society.

Third, for economic, political and social reasons, a rich man is not easily satisfied with one wife. He has the property to pay bridewealth for additional wives, whom he needs to produce many children, especially sons to inherit, expand and protect his riches. In contrast, poor men cannot marry several wives because they cannot afford the required bridewealth. While the family is culturally obliged to pay bridewealth for the first wife, it is not supposed to meet the cost of the additional wives. A man has to use his personal resources as proof that he is rich enough to deserve more than one wife. Hence, polygyny is a symbol of wealth.

A socio-political reason is power and prestige. Since only rich men can afford to marry several wives, it is considered prestigious to be a polygynist. It is partly for this reason that past kings and chiefs of the area had more than one wife, to display their prestige, power and riches to their "subjects".

Another social justification for polygyny is the practice of levirate. As discussed above, men are culturally bound to inherit wives of their deceased brothers. This is part of the mutual obligations between brothers in an extended family. The advantage of the custom is to commit men to supporting the widows of their brothers and their children. Most of the inherited women are still fecund. Their reproductive process therefore continues with minimum interruption.

Furthermore, men marry several wives for sexual pleasure and comfort. When first wives become old they lose some of their sexual appeal. Most men would still be sexually active and in some cases more demanding of sexual comfort from women. At that age, many men have accumulated some property and can afford to acquire another wife. They therefore take another wife who would be younger and sexually more attractive. Also, men with several wives have the advantage of enjoying continuous sexual relations with at least one of the wives if others are sick, pregnant or too weak for sex.

A last reason is that the Banyankole need second or more wives for more labor. Among the cultivators, women are a major source of labor on land. They plough the land, and sow, weed and harvest the crops. This is clearly demonstrated by the results of the 1984 survey, which show that 27.5 percent of the women currently married to the cultivating group are in polygamous unions. This is much higher than 8.2 percent for their counterparts in the Bahima (pastoralists) group. The cultivators, who are the large majority of Banyankole believe that more wives mean more labor to cultivate the land and more food to feed the family. If a woman becomes older and weak, a man in this group would acquire another one who is younger and able to replace the old one in providing the needed labor. On the other hand, the Bahima whose routine economic activities demand little of womens' labor, tend to be mainly monogamous. 
Given the above reasons, it is not surprising that 27.3 percent of the ever married women in reproductive age groups were in polygynous unions in 1984. The percentage for women of all age groups is not much different, 28.6 percent. In addition, generally a higher percentage of women in older groups was in polygynous marriages because additional wives tend to marry at higher ages than first wives.

It is interesting to note religious differences of the women married to polygynous men. All six Moslem women in the 1984 sample were in polygamous unions due to their religion tolerating men who marry up to four wives. Of the Christians, 30 percent of the Catholic women were reported in plural marriages as compared to 22 percent of the Anglicans (excluding the pastoralists who are all Anglicans and predominantly married to monogamists). The reason for the Anglican-Catholic difference is hard to find since

both religions discourage polygamy. It is possibly due to Catholic women being traditionally more conservative than Anglican women.

ii) The brother-in-law's sex rights in marriage : The third type of marriage, uncommon to most societies in Africa, has been misrepresented as polyandry by researchers foreign to Ankole. It is the practice in societies of south-western Uganda that brothers of a man have sexual rights over his wives. An Ankole elder had this to write about the custom :

"In true Kinyankole marriage the wife was shared by her husband's brothers in sexual relationship though privately. The husband did not stop his brothers going to his wife privately and he did not say anything about it, though he knew it" (Bitashoborokire, 1974).

The custom is partly justified by bridewealth, which is paid out of the family central pool. The wife paid for in this way is supposed to belong to all brothers. Even the sisters of the man are respected by the wife who frequently refers to them as her "husbands". This practice is part of the extended family system which is strong in the area. Brothers strongly believe they are of the same blood and share all things, such as clothes and pipes and hunt together. The spirit of brotherhood is so strong that if an animal attacked or killed one of them while hunting, the rest would fight it until they killed it or it finished them all. Likewise it is strongly believed that wives and children belong to the extended family, just as their ancestors are common. It is a way of keeping the family together.

According to the 1984 study, 20.8 percent of the currently married women asked claimed to have practiced the custom of being available to their brothers-in-law. It is practised by the pastoral Bahima much more than the Bairu cultivators. Two-thirds of the Bahima women in the reproductive age groups reported having practiced the custom as compared to only 8 percent of the Bairu women. This means it is still strong among the Bahima and weak among the Bairu. 
47.

\section{Bridewealth}

The history of bridewealth in Africa is a long one, which we do not intend to discuss here. Unfortunately researchers who are foreign to African cultures often do not understand the practice and misinterpret it to mean men purchasing women (Mushanga, 1970). The functions of the custom vary across cultures in Africa. For instance, in West Africa Isiugo-Abanihe (1987) justified the custom in Igboland on grounds of maintaining culture. In East Africa, some nomadic groups like the Karimojong in north-eastern Uganda, demand skins of lions and leopards from the suitor to prove his bravery.

In Ankole, the primary purpose of bridewealth is for the man to show the in-laws that he is serious and committed to marrying their daughters and she would be precious to him. It is also used as part of an exchange of gifts between the two families as they celebrate the marriage bond. In return for bridewealth, the girl's family is traditionally obliged to provide gifts, ("emihingiro") to the bride and bridegroom. As a result of this exchange of gifts, the two families, who sometimes may belong to clans hostile to one another, become customarily bonded and friendly. In addition, bridewealth gives the man's family some rights over the woman. The most important of these are rights over her sexuality and fertility. She cannot refuse her husband, nor can she claim her children if divorced or separated. Further, bridewealth is sometimes used by poor families to get property to use when the time comes to get a wife for the brother of the girl.

Unlike in many African societies, bridewealth among the Banyankole is modest and manageable by most families. The Etesots of north-eastern Uganda pay between 20 and 30 cattle. In contrast, until recently two cows and three goats used to be the normal bridewealth in Ankole. In any case, it is the responsibility of the father of the man to pay it. In the unlikely event of a family where the man cannot afford bridewealth, the girl's family would give her to the young man on credit. After the wedding the young man would look for employment and work to pay off the loan. This low bridewealth encourages young men and women to marry when ready.

However, there is a tendency to ask more from richer families. Also rich families have a tendency to raise bridewealth to eliminate poor suitors from marrying their daughters. This tends to raise the age at marriage of those poor men who must work for a long time before finally getting enough property to pay. But there are very few cases of this.

Recently, bridewealth has become commercialized by some families. Due to the influence of the neighboring societies of Rakiga and Bahororo, who often value their girl's education from primary school to unversity and pass on the expenses to the suitor, some Banyankole families have hiked bridewealth beyond many men's financial ability. Fortunately, the young men have responded to this new development by teaming together and raising funds from relatives and friends in order to marry when ready, rather than waiting and losing their fiances. Given the spirit of communalism which already exists in Ankolean culture, it was easy for the society to embrace the idea of raising bridewealth and wedding expenses this way. One can therefore not 
claim that the increase in bridewealth has delayed women's marriage.

The traditional response of a young man to unfairly high bridewealth is to elope with his suitor. There are seveal types of elopment in the society which this paper does not intend to discuss. Suffice it to mention that elopement is common in Ankole. Its major advantage to young men is that it allows them time to enjoy some of the benefits of marriage while looking for bridewealth. However, elopement seldom persuades the girl's parents to reduce bridewealth. In most cases, it is costly because a fine has to be paid in addition to the bridewealth.

\section{CONCLUSION}

In this paper, marriage patterns and systems in Ankole have been discussed. They include mean age at first marriage which has increased from 18 to 22 between 1969 and 1985, mainly due to dramatic increases in the proportion educated females and a wider spread of Christianity. Evidence was presented to show that variations in levels of female education, religion, childhood residence and pattern of women's work were largely responsible fo the differentials in the mean age at marriage.

Further, it has been found that a high percentage of women is in unions because of strong promarriage traditions in the area. On the other hand, divorce and separation occur despite efforts by the society to discourage them. Fortunately, there is a high rate of remarriage. In addition, although there is a high adult male mortality rate, the level of widowhood is reduced by levirate, which exists in the area.

Also, the study has identified and explained three types of marriages in the area. Most women are married to monogamous men, however polygyny is still strong, especially among the cultivators. In addition, a large proportion of the pastoral women claimed to have had sexuel relations with their brothers-in-law, in accordance with a custom that gives the latter sexual rights over the former.

Lastly, the paper discusses bridewealth. In general, the level of bridewealth is low. Hence, the cost is not prohibitive enough to delay marriages of young men and women.

It seems apparent from the study that most of the patterns of marriage discussed above are largely responsible for sustaining high fertility in Ankole. However, the impact of the different types of marriage on fertility in the area is not clear.

Our foregoing discussion has raised some questions which require more information to answer them. It is necessary to collect more data on pathological sterility of women, especially its differentials between economic groups in the area. In addition, there is need for studies that trace a woman from the time she is married through dissolution and remarriage and the number of children she gets from each marriage. Also, the type of union and its timing in a woman's marriage life and childbearing career will help to determine the influence of polygamy on fertility. Lastly, research into how marriage factors of fertility are changing should be conducted. 
49.

\section{REFERENCES}

Arya, O.P., H. Nsanzumuhire, and S. Taber 1973, "Clinical cultural and demographic aspects of gonorrhoes in rural community in Uganda", Bulletin of the World_Health Organization. vol. 49: 587-595

, 1980, "Gonorrhoea and infertility in rural Uganda" American Journal of Obstetrics and Gvnaecology. 138:929-932

Bitashoborokire, Y., 1974, "The Kinyankole traditional marriage", Occasional Paper $n^{\circ}$ 223. In : African Traditional Religion and Philosophy 22, Department of Philosophy and Religious Studies, Makerere University, Kampala, Uganda.

Bongaarts J. and R. Potter, 1983, Fertilitv. Biologv and Behavior. An Analvsis of the Proximate Determinants Academic Press, New York.

Byaruhanga-Akiiki, 1978, "The problem of monogamy and polygamy today : Bantu case, Africa", Occasional Paper $n^{\circ}$ 306. In : African Traditional Religion and Philosophv. 32, Department of Philosophy and Religious Studies, Makerere University, Kampala, Uganda.

Costello, C.A., 1986, Maternal and child health in rural Uganda: The role of nutrition, Ph.D. dissertation in demography, University of Pennsylvania, Philadelphia.

Davis, K. and J. Blake, 1956, "Social structure and fertility : An analytic framework", Economic Develonment and Cultural Change, 4(4): 211-235

Economic Commission for Africa, 1979, "How high is fertility in Africa". In : Population Dvnamics : Fertility and Mortality in Africa. Proceedings of the Expert Group Meeting on Fertility and Mortality Levels and Trends in Africa and Their Policy Implications, Monrovia, Liberia, 26 November - 1 December, UNECA 
Elam, Y., 1973, The Social and Sexual Roles of Hima Women, Manchester University Press

Hajnal, J., 1953, "Age at marriage and proportions marrying", Population Studies. 7:111-132

Isiugo-Abanihe, U.C., 1987, "High bridewealth and age at marriage in Igboland". In : Cultural Roots of African Fertility Regimes. Proceedings of the Ife Conference, February 25-March 1.

Katende, J., 1983, Housing conditions and some of the related socio-economic and demographic aspects : a case of Bushenyi district, Uganda, M.A. thesis, University of Nairobi, Kenya.

Mushanga, M.T., 1970, "Polygyny in Kigezi", Uganda Journal, 34 (2): 201-209

Ntozi, J.P.M., 1984, Family and Fertility in Uganda, paper presented at a Workshop on Population Growth and Socio-economic Development in Uganda, Mweya Safari Lodge, Queen Elizabeth National Park, Uganda, June 25-29

Ntozi, J.P.M., J.B. Kabera, J. Mukiza-Gapere, J. SsekamatteSebuliba, and J. Kamateeka, 1986, "Some aspects of the determinants of fertility in Ankole, Uganda : findings of the elders survey", manuscript, Makerere University, Kampala, Uganda.

Pebley, A.R., 1986, "Marriage patterns and demographic change in sub-Sahara Africa", paper presented at the annual meeting of the PAA, San Francisco, California, April 3-5.

Pison, G., 1987, "Polygyny, fertility and kinship in the region of sub-Sahara Africa". In : Cultural Roots of African Fertilitv Regimes. Proceedings of the Ife Conference, February 25-March 1. 
Republic of Kenya, 1980, Kenva Fertility Survev. 1977-1978. First Report. 1, Chapters 4 and 5, Central Bureau of Statistics, Ministry of Planning and Development Nairobi, Kenya

Republic of Uganda, 1973, Report on the 1969 Uganda Census. III, Additional Tables. The Statistics Division, Ministry of Finance, Planning and Economic Development, Entebbe, Uganda

, 1976, Report on the 1969 Population Census. vol. IV, The Analytical Renort. The Statistics Division, President's Office, Entebbe, Uganda

Sheku, B.V., 1987, Pathological determinants of sterility in rural Uganda, Ph.D. dissertation in demography, University of Pennsylvania, Philadelphia.

Uganda Protectorate, 1961, Uganda Census. 1959. African Population, Statistics Branch, Ministry of Economic Affairs, Entebbe, Uganda

United Nations, 1983, Indirect Techniques for Demographic Estimation. Manual X, United Nations, New York. 